\title{
EFECTO DE AUXINAS Y CITOQUININAS EN EL CULTIVO DE TEJIDO DE AHNFELTIA PLICATA (HUDSON) FRIES, 1836 (AHNFELTIALES, RHODOPHYTA) DE LA REGIÓN DE MAGALLANES
}

\author{
EFFECTS OF AUXINS AND CYTOKININS ON TISSUE CULTURE \\ OF AHNFELTIA PLICATA (HUDSON) FRIES, 1836 (AHNFELTIALES, \\ RHODOPHYTA) FROM MAGELLAN REGION
}

Fabiola Villanueva ${ }^{1}$, M. Ávila ${ }^{1}$, Andrés Mansilla ${ }^{2,3}$ S. Abades ${ }^{3,4}$ \& J. Cáceres ${ }^{1}$.

\begin{abstract}
RESUMEN
Ahnfeltia plicata (Hudson) Fries, 1836, es una agarófita comercialmente importante, que ocurre en la Región de Magallanes y caracterizada por presentar un ciclo de vida heteromórfico. Se han utilizado técnicas de cultivo in vitro para la micropropagación de diferentes especies de microalgas, sin embargo, no hay antecedentes del uso de estas tecnologías con A. plicata. El objetivo de este estudio fue desarrollar técnicas de cultivo in vitro de tejido vegetativo de A. plicata para micropropagación utilizando 2 reguladores de crecimiento de plantas superiores: 6-Bencilaminopurina (BAP) y ácido Indolacético (IAA) bajo diferentes condiciones de cultivo. Fueron utilizados talos gametofíticos no reproductivos de regiones apicales y porciones medias, de los cuales se obtuvieron explantes de $5 \mathrm{~mm}$. Los reguladores de crecimiento de plantas superiores fueron utilizados en 3 concentraciones: $0.1 \mathrm{mg} / \mathrm{L}, 1.0 \mathrm{mg} / \mathrm{L}$ y $5.0 \mathrm{mg} / \mathrm{L}$, preparadas en medio de cultivo Provasoli. El experimento se realizó en triplicado para cada concentración de estos reguladores de crecimiento y para cada sección del talo, utilizando un $n=4$ explantes por placa de cultivo en dos fotoperiodos (16:8 y 12:12, luz: oscuridad), a una temperatura de $10^{\circ} \mathrm{C}$ e intensidad luminosa de 9 - $10 \mu \mathrm{mol} \mathrm{seg-1} \mathrm{m-2.} \mathrm{Se} \mathrm{realizaron} \mathrm{monitoreos} \mathrm{y} \mathrm{mediciones} \mathrm{de} \mathrm{cada} \mathrm{explante} \mathrm{cada} \mathrm{siete} \mathrm{días.} \mathrm{Se} \mathrm{observó}$ que ambos reguladores de crecimiento de plantas superiores promueven el crecimiento de Ahnfeltia plicata. El medio de cultivo enriquecido con IAA estimuló el crecimiento en regiones polares de los explantes de A. plicata, mientras que al utilizar BAP se observó crecimiento tanto en regiones polares como formación
\end{abstract}

\footnotetext{
${ }^{1}$ Instituto de Ciencia y Tecnología, Universidad Arturo Prat. Ejército 443, Puerto Montt, Chile.

2 Departamento de Ciencias y Recursos Naturales, Facultad de Ciencias, Universidad de Magallanes, Punta Arenas, Chile.

${ }^{3}$ Instituto de Ecología y Biodiversidad (IEB) Chile

${ }^{4}$ Pontificia Universidad Católica de Chile
} 
de ramificaciones laterales. El proceso de regeneración de explantes mostró mejor resultados con BAP $1 \mathrm{mg} / \mathrm{L}$ en fotoperíodo 12:12 (luz: oscuridad). Los tejidos cultivados en fotoperiodo corto, presentaron decoloración y mayor porcentaje de mortalidad.

Palabras clave: auxinas, citoquininas, Ahnfeltia plicata, micropropagación, callos.

ABSTRACT

Ahnfeltia plicata (Hudson) Fries, 1836, is a commercially important agar producer which occurs in the Magallanes region, characterized by an heteromorphic life-cycle. Several in vitro growth techniques have been used for the micropropagation of different genotypes of macroalgae. Nevertheless, there are no records of work undertaken with A. plicata. The objective of this research was for the development of in vitro growth techniques of A.plicata vegetative tissue for micropropagation using 2 plant growth substances: 6- Bencilaminopurine (BAP) and Indolacetic acid (IAA) under different culture conditions. Non reproductive gametophyte thalli from apical and intermediate portions were used, from where $5 \mathrm{~mm}$ explants were obtained. Plant growth substances were used in 3 concentrations: $0.1 \mathrm{mg} / \mathrm{L}, 1,0 \mathrm{ng} / \mathrm{L}$ and $5.0 \mathrm{mg} / \mathrm{L}$, all prepared within a Provasoli culture media. The experiment was undertaken threefold for each hormone concentrate and for each explant, using $n=4$ for each growth Petri dish in two photoperiods $16: 8$ and $12: 12$, (light: darkness) with a temperature of $10^{\circ} \mathrm{C}$ and a light intensity of $9-10 \mu \mathrm{mol}$ seg- 1 m-2. Monitoring and measurements for each explant were undertaken every seven days. It was observed that both plant growth substances enhanced growth of Ahnfeltia plicata. The growth media enriched with IAA enhanced the growth in polar regions of the A. plicata explants while the use of BAP showed both growth in polar regions and side branches. The explants regeneration process evidenced better results with BAP $1 \mathrm{mg} /$ Lt with a photoperiod of 12:12 (light:darkness) The tissues grown in short photoperiods evidenced larger decoloration and a greater percentage of mortality.

Key words: auxins, cytokinins, Ahnfeltia plicata, micropropagation, callus-like structures

\section{INTRODUCCIÓN}

El estudio de técnicas de cultivo de tejido y protoplastos en macroalgas rojas ha sido de gran interés para la manipulación genética y la micropropagación, tanto para mejorar los cultivos acuícolas como para incrementar el conocimiento acerca de procesos de diferenciación, morfogénesis y regeneración (Yokoya \& Handro, 1996) y desarrollo de productos de interés comercial (Reddy et al., 2008).

Desde la década del 70 se han aplicado las técnicas de cultivo in vitro para propagación de tejidos en diversas algas (Chen \& Taylor, 1978), de interés económico. Los primeros estudios establecieron las bases para desarrollar el conocimiento de las tecnologías para producción y regeneración de callos (Polne-Fuller, 1988, Butler \& Evans, 1990, García Reina et al., 1991). El avance en el conocimiento tanto sobre la regulación hormonal como de la importancia de los diferentes factores sobre los procesos fisiológicos en algas rojas, han jugado un papel fundamental para obtener éxito en la propagación in vitro de muchas especies (Polne-Fuller \& Gibor, 1987; Yokoya \& Handro, 1997; Reddy et al., 2008). Si bien se conoce la importancia de reguladores de crecimiento sobre procesos fisiológicos en plantas superiores (PGR), el efecto de diferentes concentraciones de PGR en macroalgas aún es poco conocido, probablemente por la falta de conocimiento del rol fisiológico de estas sustancias en el crecimiento y diferenciación de algas (Evans \& Trewavas, 1991, Yokoya \& Handro, 1996). Se ha descrito en la literatura que en las algas ocurren fitoreguladores de crecimiento de plantas superiores y citoquininas en concentraciones similares a plantas superiores (Reddy et al., 2008), otros autores señalan que estas sustancias podrían provenir de bacterias y otros microorganismos, presentes en los cultivos. Se han detectado varios productos como metabolitos secundarios de los microorganismos que podrían estar promoviendo o inhibiendo el crecimiento de las algas en ensayos de laboratorio (Evans \& Trewavas, 1991).

Ahnfeltia plicata (Hudson) Fries, 1836, es 
una de las principales agarófitas comercialmente importantes del mundo. Su distribución en Sudamérica es: en Chile: Magallanes y Tierra del Fuego (Cabo de Hornos: Rada de Goreé); Bahía Slogget; Seno Almirantazgo (Caleta María); Puerto Pomar (Aguas de Otway); Estrecho de Magallanes y Canal Fitzroy. En Perú: Lima, Callao (Ramírez \& Santelices, 1991) e Islas Falkland. En Uruguay: Nordeste Atlántico, desde el ártico hasta Portugal (Cabioch, 1992). En el Ártico: Canadá. En Europa: Mar Báltico, Gran Bretaña, Dinamarca, Groenlandia, Francia, Helgoland, Islandia, Irlanda, Países bajos, Noruega, Portugal, Escandinavia, España, Spitsbergen y Suecia. En Islas del Atlántico: Ascension y Azores. En Norteamérica: Alaska, California, México y new Brunswick. En Sudeste Asiático: India, Irán, Pakistán y Sri Lanka. En Asia: Rusia. En Antártica e islas subantárticas: Antártica, Isla Crozet, Graham Land, Kerguelen, Isla Macquarie, Georgia del Sur y Tierra del Fuego.

En Rusia, ha sido explotada como una fuente de agar de alta calidad y bajo contenido de sulfato (Maggs \& Pueschel, 1989). Esta especie ocurre también en las costas de la Región de Magallanes y en forma similar a las poblaciones de Rusia, parece presentar un ciclo de vida heteromórfico. El objetivo de este estudio fue estudiar el efecto de dos tipos de reguladores de crecimiento de plantas superiores de crecimiento 6- Bencilaminopurina (BAP) (citoquinina) y ácido Indolacético (IAA) (auxina), y desarrollar técnicas de cultivo in vitro de tejido intercalar y apical de A. plicata para su micropropagación, para la obtención de crecimiento de talos vegetativos en laboratorio y hatchery para un posible cultivo piloto en el mar

\section{MATERIAL Y METODOS}

Se obtuvieron ejemplares de A. plicata de poblaciones naturales, Seno Skyring, Isla Riesco (5238'59.7”S; 7129'44”W) Región de Magallanes en Octubre de 2010. De cada ejemplar se cortaron trozos de talos gametofíticos no reproductivos de $3 \mathrm{~cm}$ de dos porciones del talo: porcion apical y porción media del talo, los cuales fueron sonicados y enjuagados con solución betadina $0,5 \%$, con el fin de eliminar epífitos y microorganismos (indicar autor). Posteriormente, fueron tratados por 48 horas con penicilina/nistatina (Villanueva et al., 2010), con el fin de eliminar bacterias y hongos, a una temperatura de $10^{\circ} \mathrm{C}$ y con un fotoperiodo de 16:8 L: O (Luz: Oscuridad). Transcurrido ese tiempo, cada segmento fue cortado en explantes de aproximadamente $5 \mathrm{~mm}$ para los experimentos de crecimiento con reguladores de crecimiento de plantas superiores. Para el tratamiento control, se tomaron segmentos de talos gametofíticos no reproductivos, los cuales fueron lavados en agua de mar esterilizada y cultivados en medio de cultivo Provasoli (PES). Se utilizaron dos reguladores de

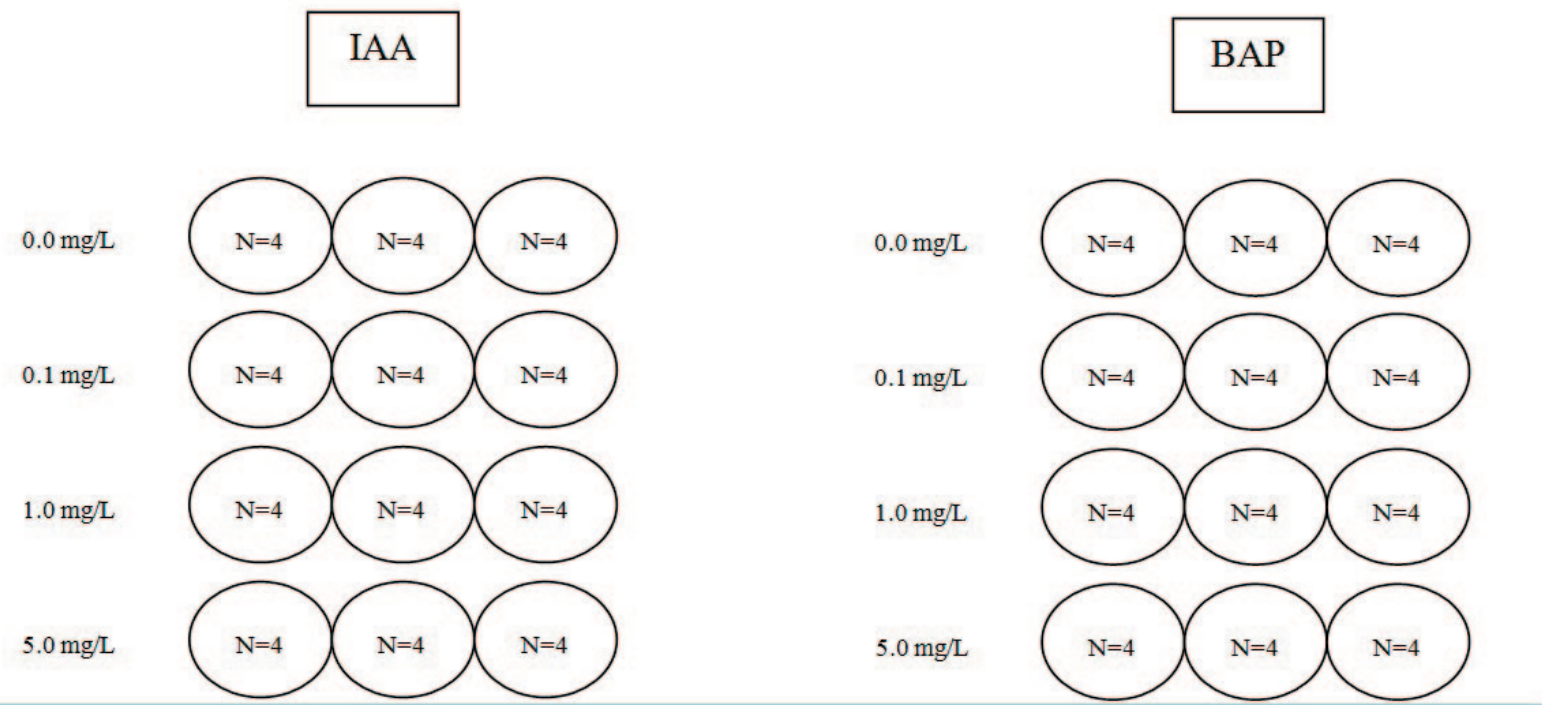

Fig. 1. Diseño experimental de experimento con A. plicata utilizando dos sustancias reguladoras de crecimiento en plantas: IAA y BAP. Controles: Provasoli sin TRIS buffer, indicados como $0.0 \mathrm{mg} / \mathrm{L}$. 
crecimiento de crecimiento, IAA (auxina) y BAP (citoquinina), a 3 concentraciones: $0.1 \mathrm{mg} / \mathrm{L}, 1.0$ $\mathrm{mg} / \mathrm{L}$ y $5.0 \mathrm{mg} / \mathrm{L}$, preparadas en medio de cultivo Provasoli (PES) (McLachlan, 1973). El experimento se realizó en triplicado para cada concentración de reguladores de crecimiento y para cada sección del talo, utilizando un $n=4$ explantes por placa de cultivo en dos fotoperiodos (Fig. 1).

A. Tratamiento 1. Fotoperíodo 16:8 (luz oscuridad), con una temperatura de $10^{\circ} \mathrm{C}$ y una intensidad luminosa de 9 - $10 \mu \mathrm{mol}$ seg- $1 \mathrm{~m}-2$.

B. Tratamiento 2. Fotoperíodo 12:12 (luz oscuridad), con una temperatura de $10^{\circ} \mathrm{C}$ y una intensidad luminosa de 9 - $10 \mu \mathrm{mol}$ seg- $1 \mathrm{~m}-2$. Figura 1

Durante el estudio, los cambios de medio de cultivo enriquecido con sustancias reguladoras de crecimiento se realizaron semanalmente. Se evaluó el crecimiento mediante fotografías tomadas cada 15 días bajo lupa estereoscópica marca Zeiss modelo Stemi DV4 a 12X utilizando el programa ImageJ, Una vez finalizada la etapa experimental, se comparó el crecimiento de los diferentes tratamientos experimentales a través de un análisis de varianza de 3 factores (ANDEVA).

\section{RESULTADOS}

El porcentaje de sobrevivencia promedio durante el experimento fue de $79,2 \%$, de los explantes provenientes tanto de porciones apicales como de porciones medias de los talos de A. plicata. En cuanto a las condiciones de cultivo, se observó una mayor sobrevivencia en aquellos explantes cultivados bajo condiciones de fotoperíodo de día largo16:8 (Luz: oscuridad) (Fig. 2). La menor sobrevivencia $(<10 \%)$ se observó en aquellos explantes apicales e porciones medias cultivados con BAP concentración 3 (5 mg/L) y mantenidos en fotoperíodo 12:12 (luz:oscuridad) y a $10^{\circ} \mathrm{C}$, tratamiento en el cual se observó necrosis temprana de tejido a los 56 días de tratamiento $(8,33 \%)$.

En cuanto al tipo de crecimiento presentado por los explantes de A. plicata como respuesta al

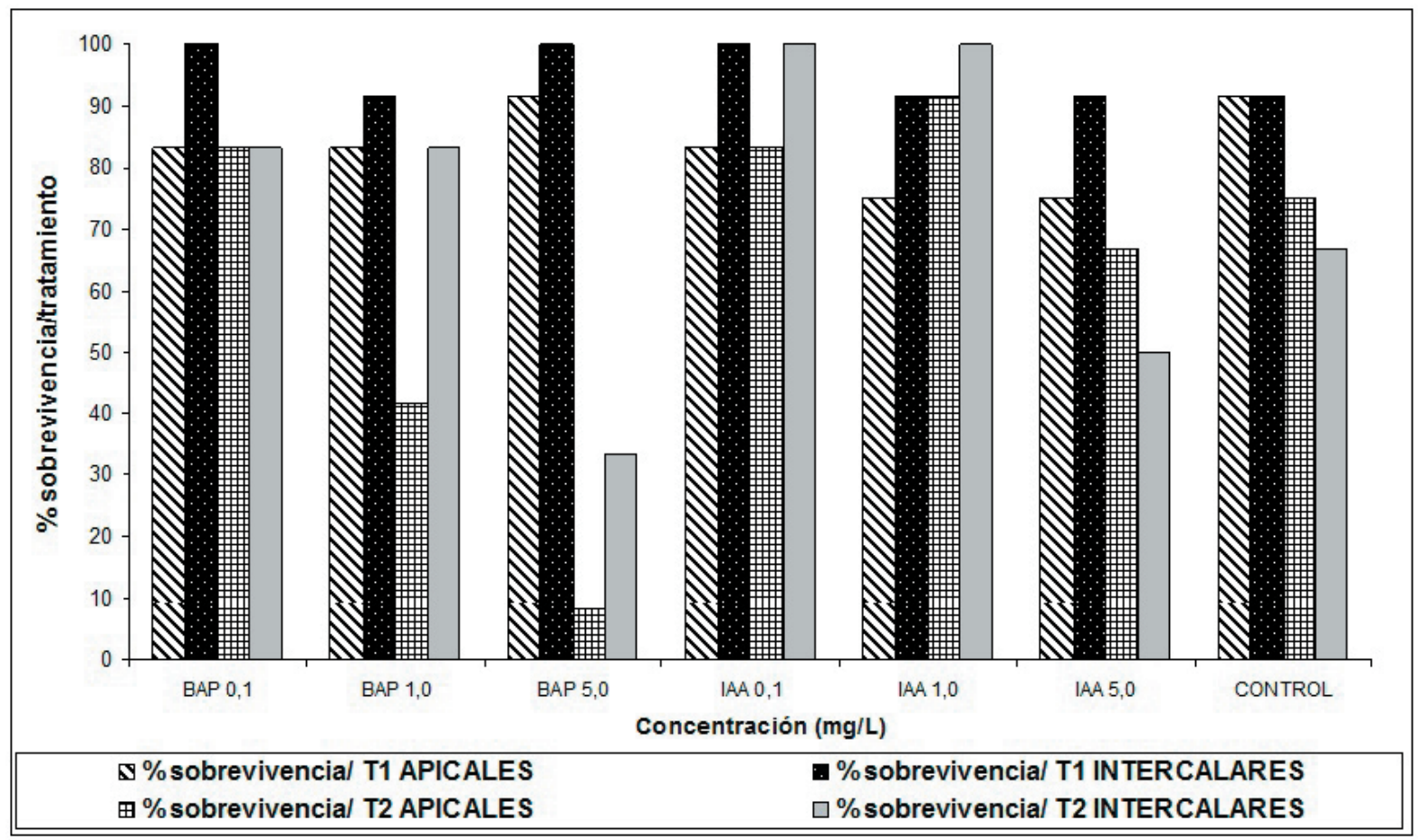

Fig. 2. Porcentaje de sobrevivencia de explantes de regiones apicales e intercalares (porciones medias) de talos de A. plicata en tratamientos 1 y 2 , con 2 tipos de reguladores de crecimiento de plantas superiores en 3 concentraciones (BAP = 6bencilaminopurina; IAA = Ácido Indolacético). 
TABLA 1. Efectos sobre cambios en talla de las regiones apicales de A. plicata (ANDEVA). Se destacan dos interacciones significativas. F: Fotoperíodo; T: tiempo (semanas) y H: tratamiento hormonal.

\begin{tabular}{lcccccc}
\hline Efecto & gl efecto & CM efecto & gl error & CM error & F & p \\
\hline Fotoperíodo (F) & 1 & 29,86 & 248 & 0,40 & 74,610 & $<0,001$ \\
Hormona (H) & 6 & 5,81 & 248 & 0,40 & 14,518 & $<0,001$ \\
Tiempo (T) & 8 & 2,63 & 248 & 0,40 & 6,582 & $<0,001$ \\
Fx H & 6 & 3,34 & 248 & 0,40 & 8,352 & $<0,001 *$ \\
Fx T & 8 & 0,76 & 248 & 0,40 & 1,894 & 0,061 \\
Hx T & 48 & 0,65 & 248 & 0,40 & 1,617 & $0,010 *$ \\
Fx H x T & 48 & 0,54 & 248 & 0,40 & 1,358 & 0,071 \\
\hline
\end{tabular}

efecto de sustancias reguladoras de crecimiento de plantas superiores estudiadas, se observó que aquellos

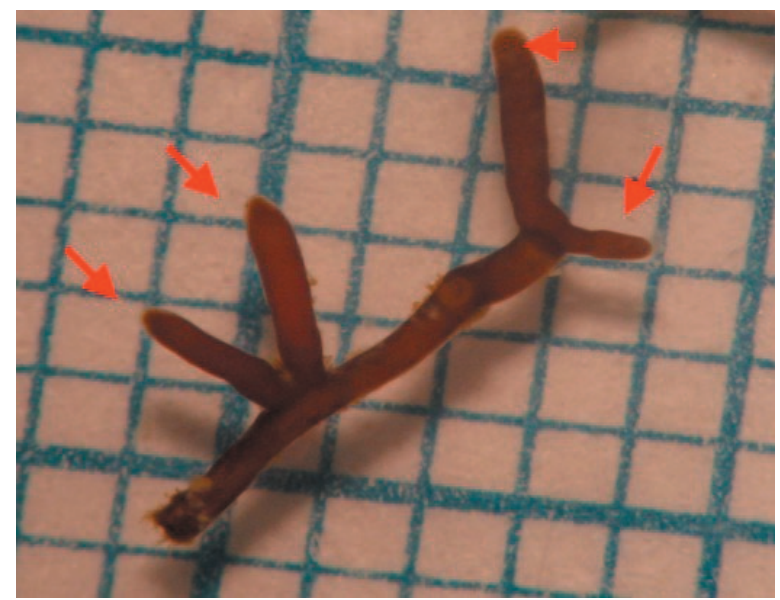

Fig. 3. Crecimiento de explantes de región apical de A. plicata con BAP. Ramificaciones laterales (aumento: 8X).

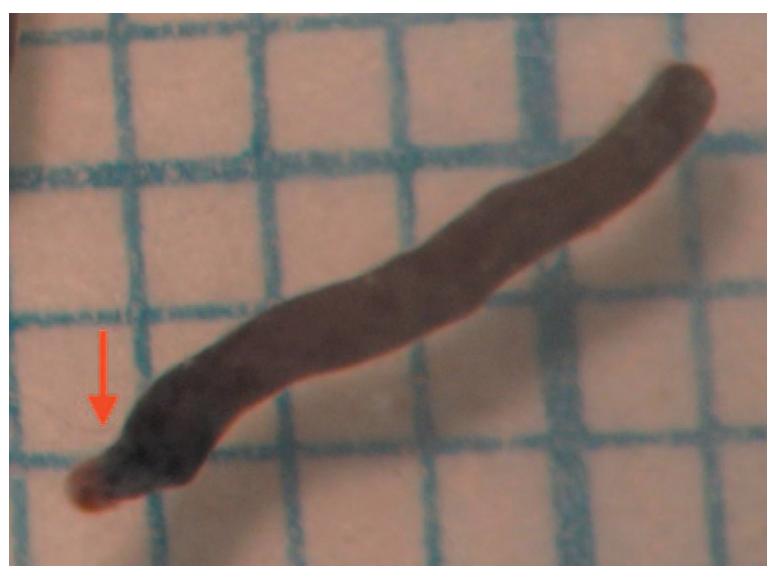

Fig. 4. Crecimiento de explantes de región apical de A. plicata con BAP. Crecimiento polar (aumento: 32X). cultivados con hormona BAP se caracterizaron por presentar tanto crecimiento en los polos o extremos de las porciones del talo, además de formación de ramificaciones laterales, en ambas regiones de corte (Fig. 3 -4). En los tratamientos con IAA, sólo se pudo observar crecimiento en los polos (Fig. 5). La formación de callos ocurrió principalmente en el tratamiento con BAP $5 \mathrm{mg} / \mathrm{L}$ mantenido en fotoperíodo 16:8 (L:O) a 10ํㅡ, donde se observó que el 25\% de los explantes de la región apical formaron callos (Fig. 6 - 9, 10). En este mismo tratamiento, la formación de ramificaciones laterales es notable. En algunos casos, se observó también la formación de una cubierta blanquecina que se denominó "cubierta hialina", la que cubrió todo el talo en ambas regiones de corte en ambos tratamientos. (Fig. 11 y 12). Se efectuaron cortes transversales, los que muestran que el tejido formado correspondería al desarrollo inicial de tejido reproductivo.

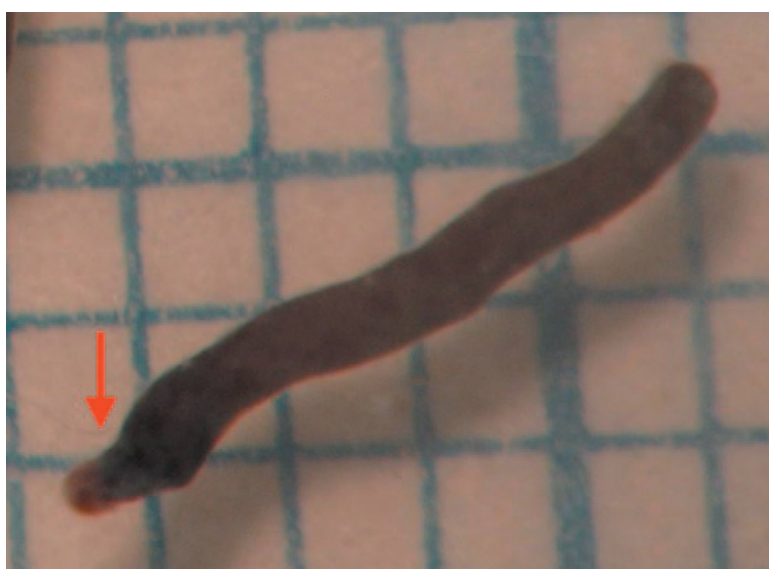

Fig. 5. Crecimiento de explantes de porción media de A. plicata con IAA. Crecimiento polar (aumento: 25X). 


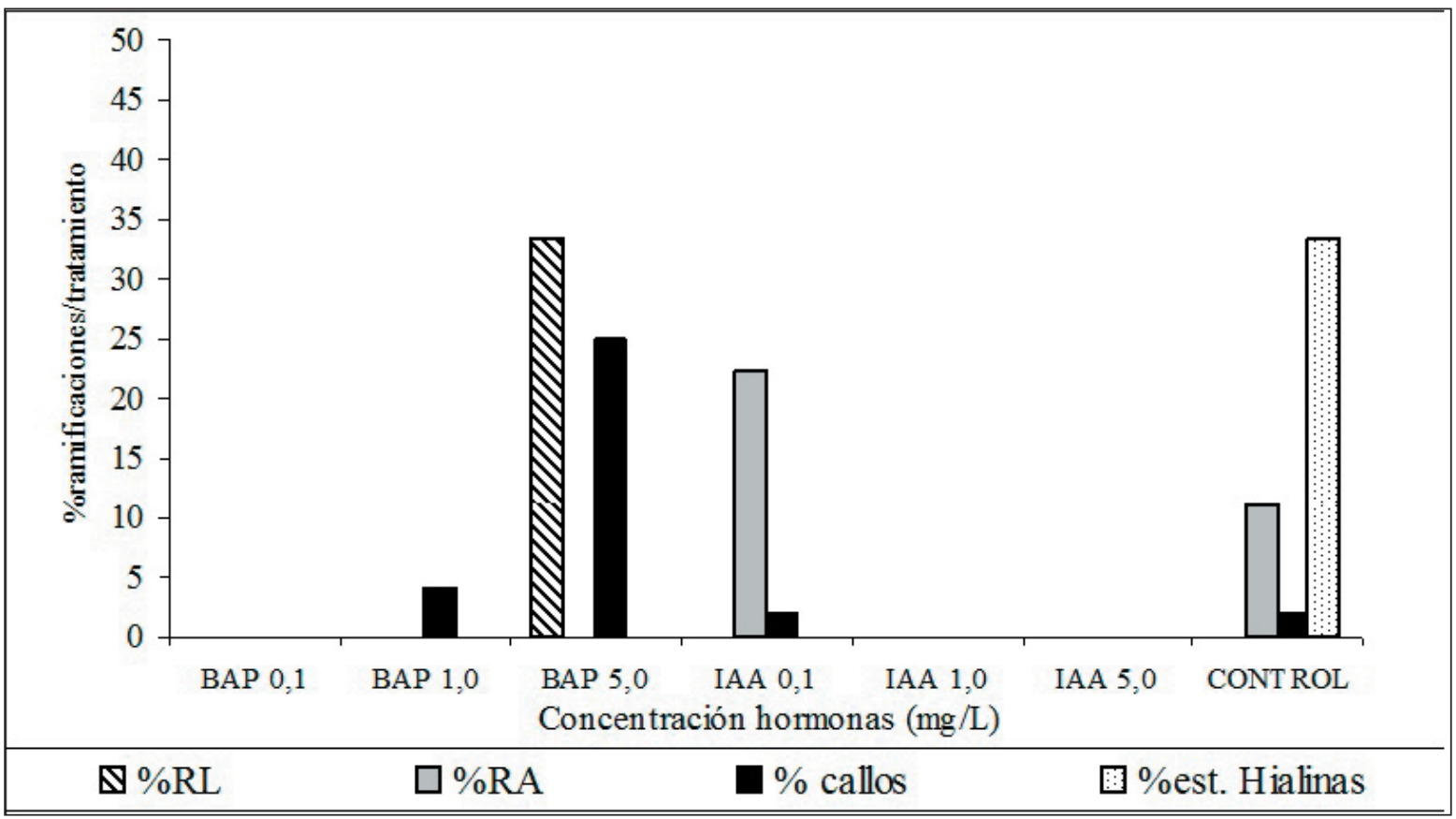

Fig. 6. Porcentaje de formación de ramificaciones, callos y estructuras hialinas en talos de región apical de A. plicata, tratamiento 1. RL: Ramas Laterales; RA: Ramas Apicales.

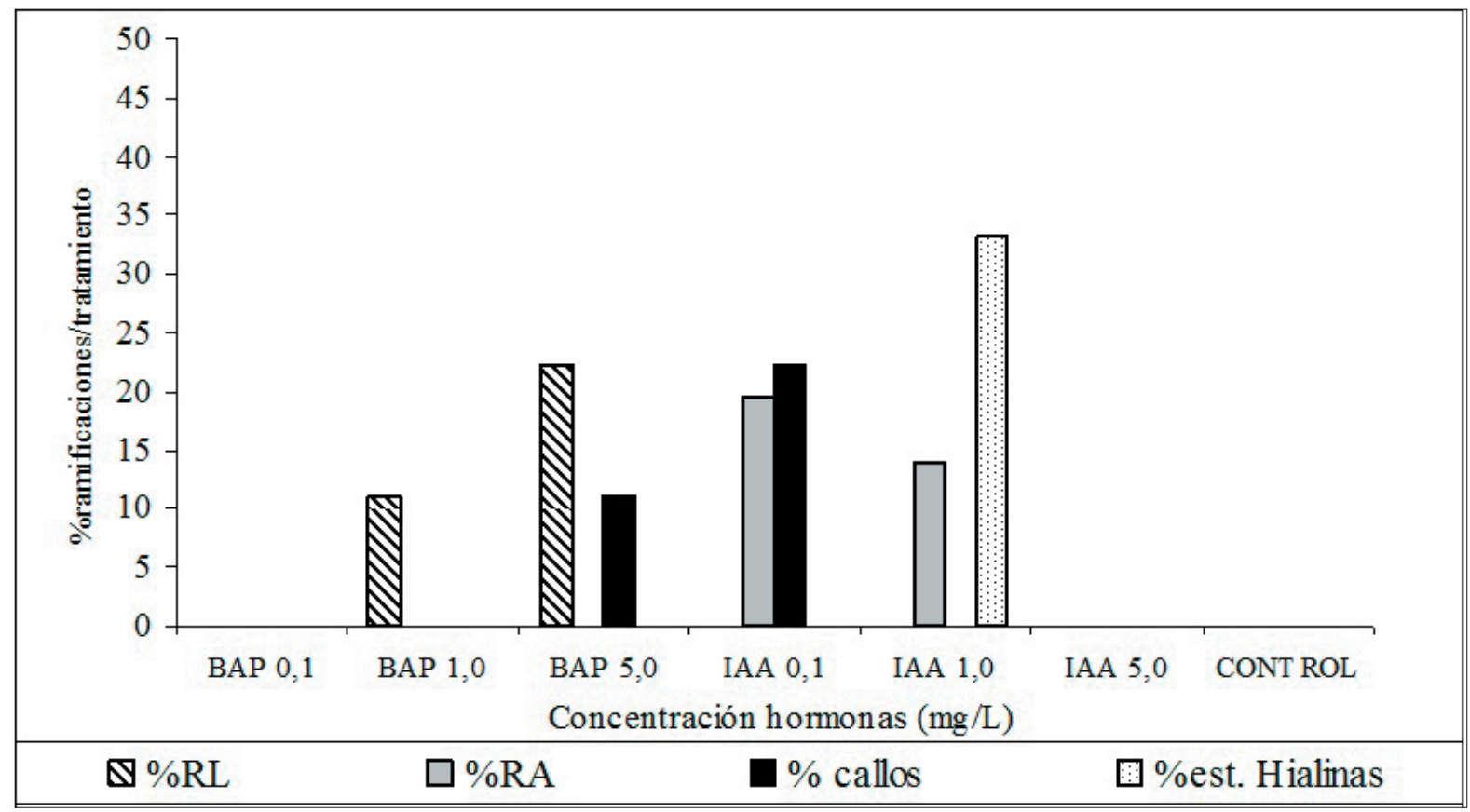

Fig. 7. Porcentaje de formación de ramificaciones, callos y estructuras hialinas en talos de porciones medias de A. plicata, tratamiento 1. RL: Ramas Laterales; RA: Ramas Apicales. 


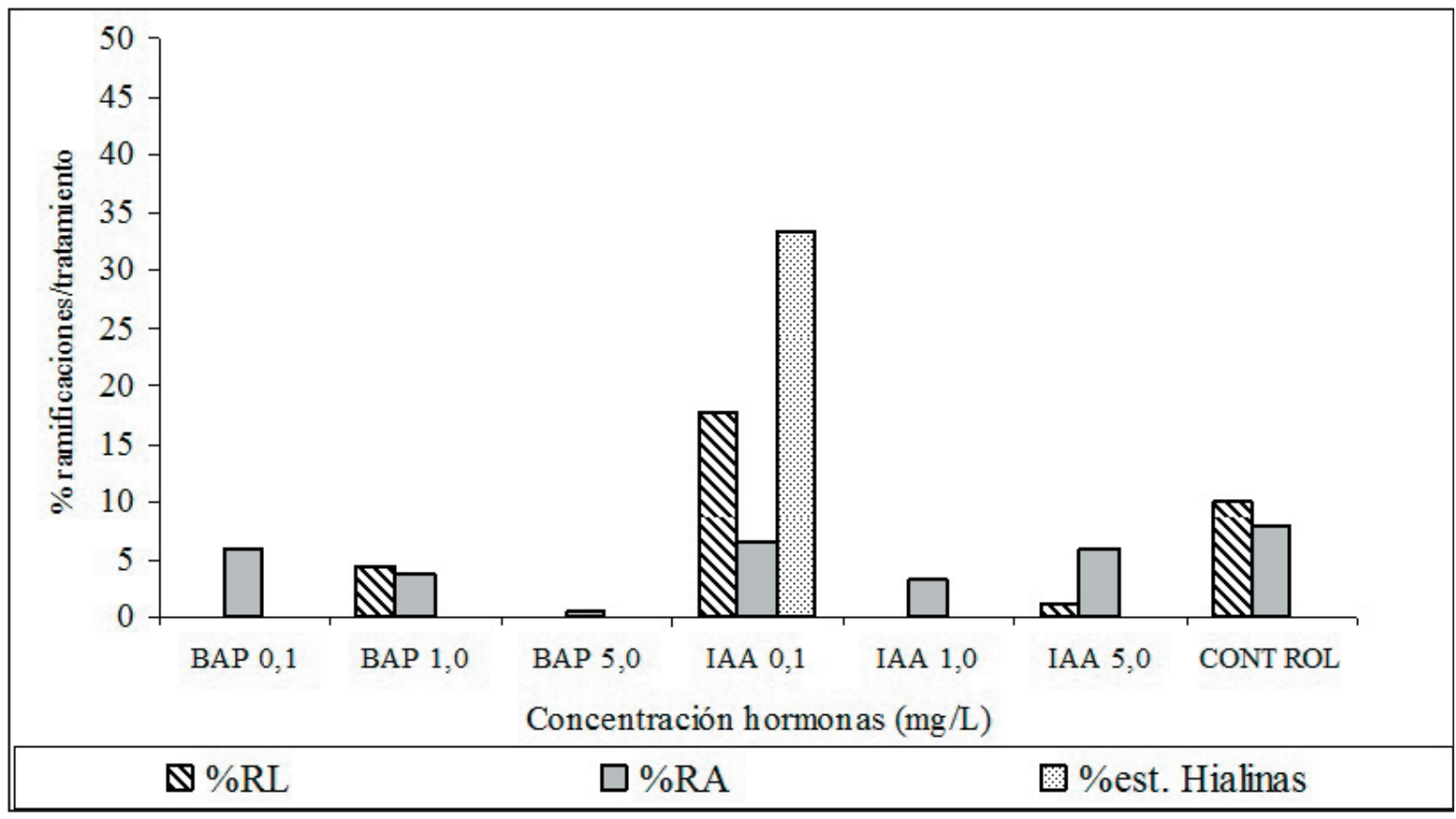

Fig. 8. Porcentaje de formación de ramificaciones, callos y estructuras hialinas en talos de región apical de A. plicata, tratamiento 2. RL: Ramas Laterales; RA: Ramas Apicales.

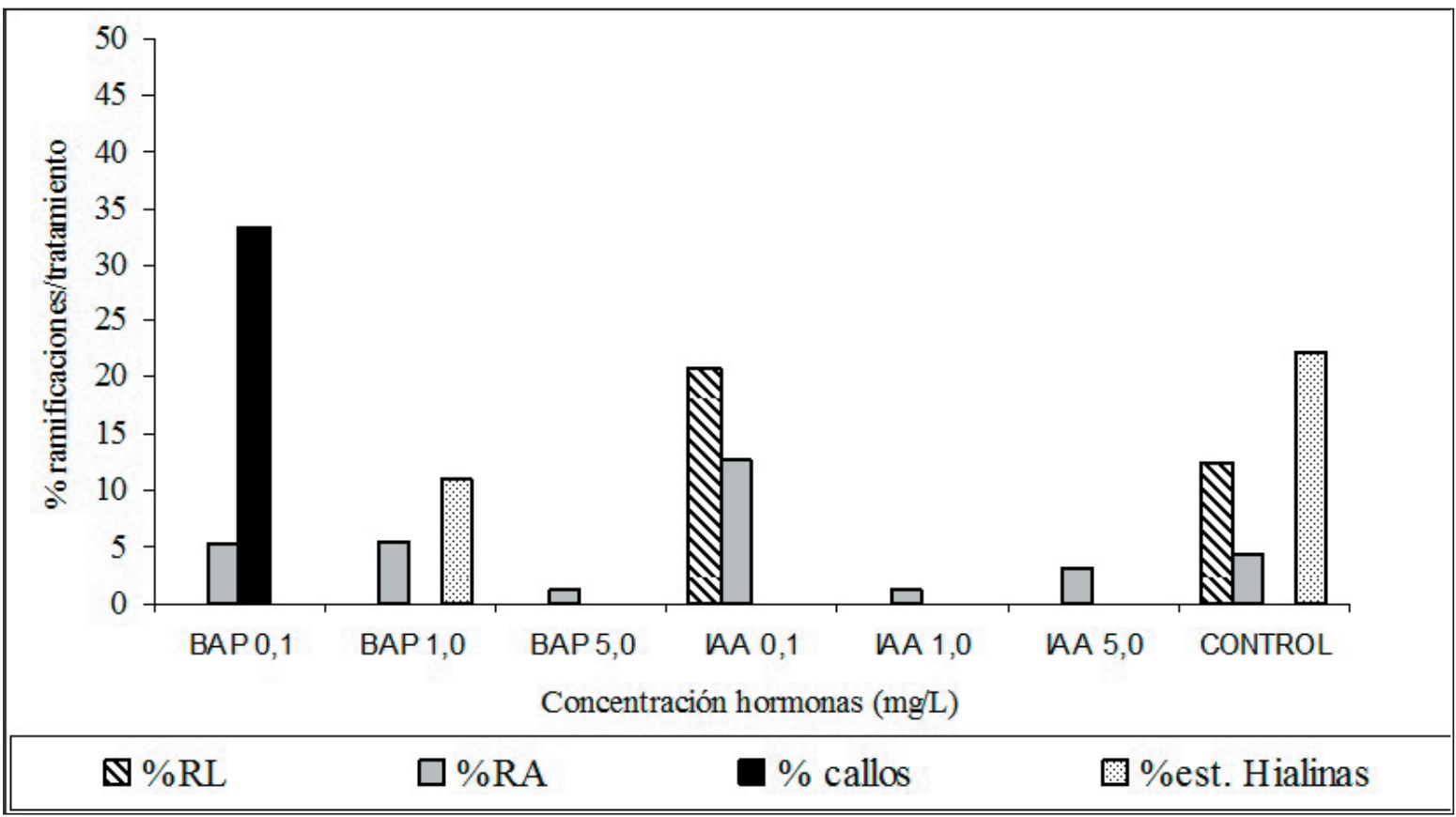

Fig. 9. Porcentaje de formación de ramificaciones, callos y estructuras hialinas en porciones medias de talos de A. plicata, tratamiento 2. RL: Ramas Laterales; RA: Ramas Apicales. 


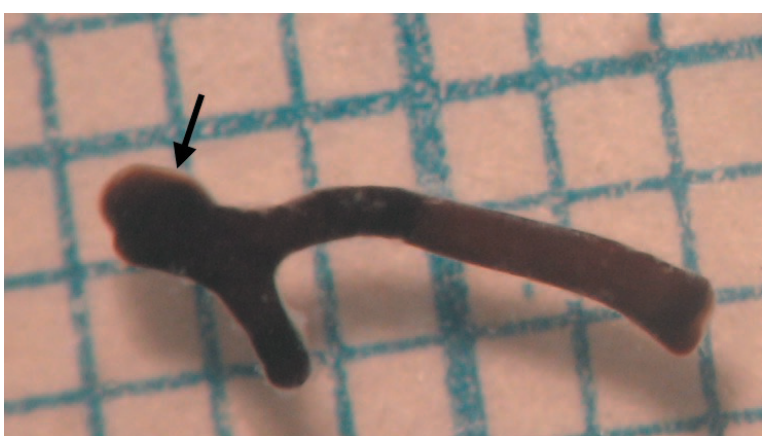

Fig. 10. Callo desarrollado en porción apical de Ahnfeltia plicata cultivado en Provasoli sin TRIS con BAP 5,0 mg/ L mantenido en fotoperíodo 16:8 (L:O) a $10^{\circ} \mathrm{C}$ (aumento: 32X).

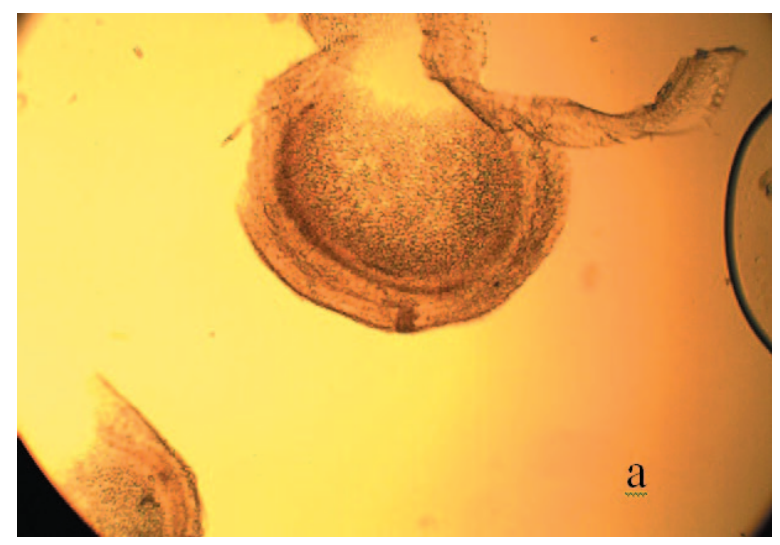

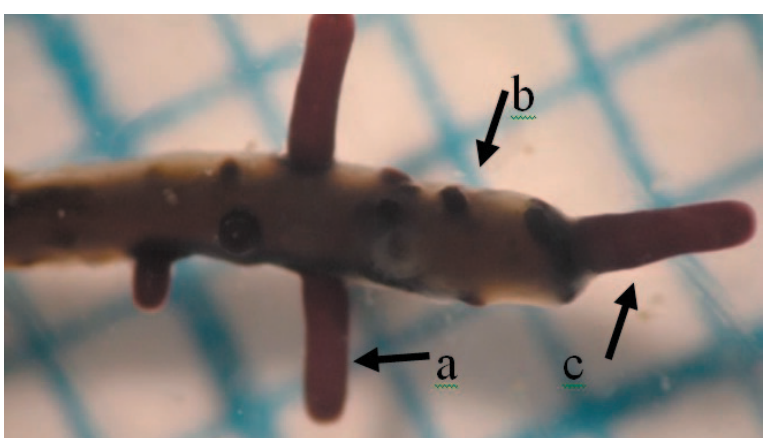

Fig. 11. Cubierta hialina desarrollada en cultivos in vitro de A. plicata. a) Ramificación lateral; b) Cubierta hialina; c) Ramificación polar (aumento: 32X).

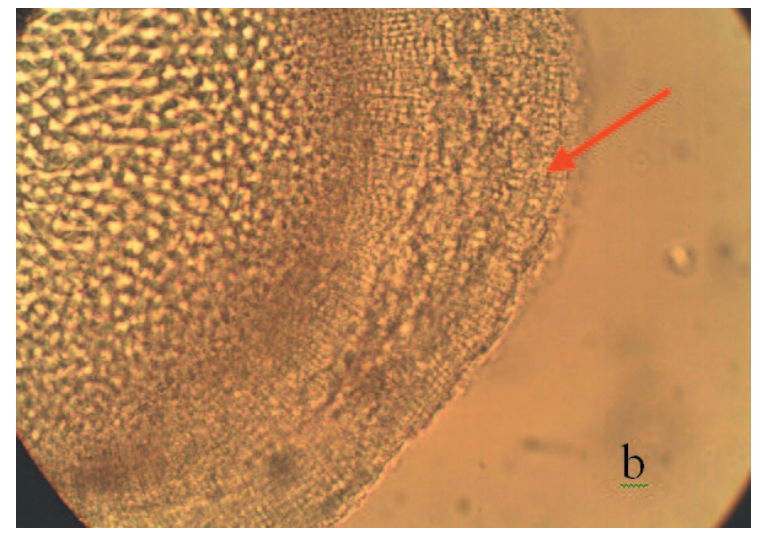

Fig. 12. Corte transversal de cubierta hialina desarrollada en cultivos in vitro de A. plicata. a) Vista general del corte (10X). b) vista detallada del corte (40X), donde se indica cubierta hialina (tejido) que recubre el talo.

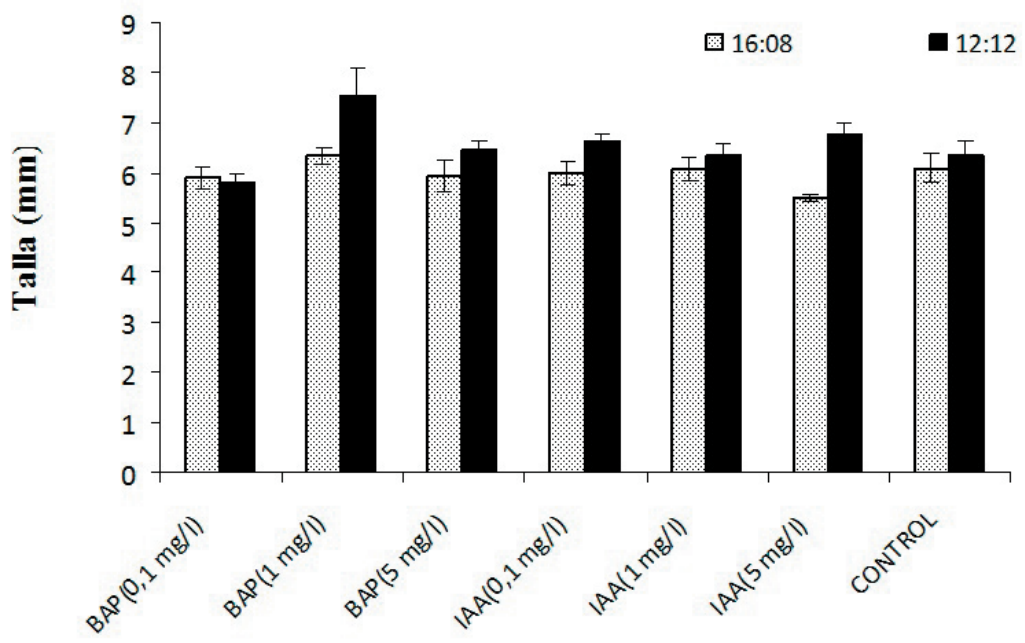

Tratamiento hormonal

Fig 13. Interacción entre reguladores de crecimiento de plantas superiores y fotoperíodo sobre la talla promedio de regiones apicales (mm) de A. plicata. Barras de error corresponden a dos errores estándar. BAP: 6-bencilaminopurina; IAA: Ácido Indolacético. 


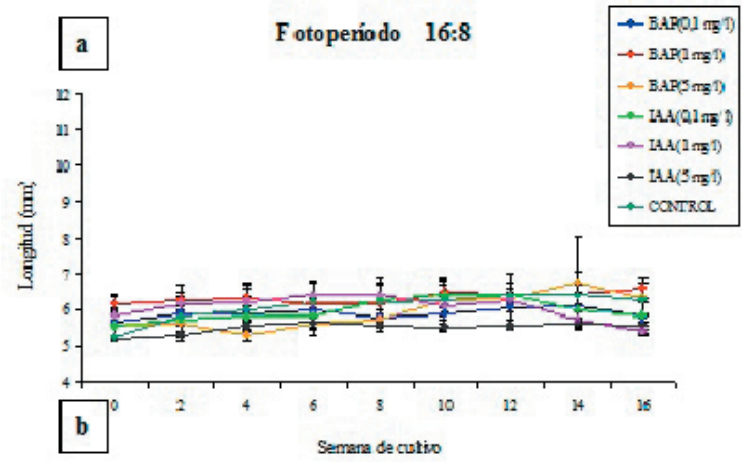

Fotoperíodo 12:12

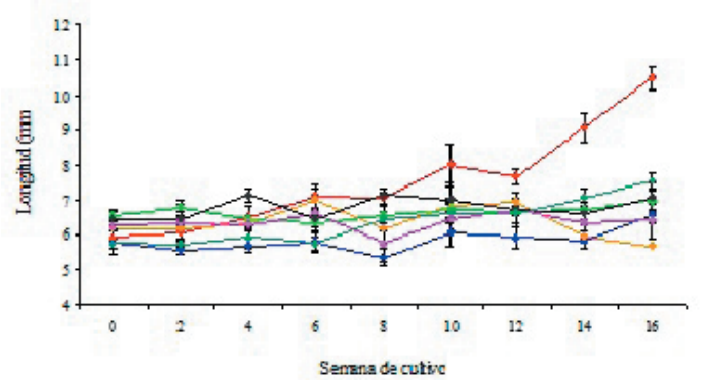

Fig.14. Efecto del tratamiento de reguladores de crecimiento de plantas superiores sobre la longitud de talos $(\mathrm{mm})$ en el tiempo (semana de cultivo) para regiones apicales de A. plicata. En distintas condiciones de fotoperíodo: a) fotoperíodo: 16:8 (L:O) y b) fotoperíodo $12: 12$ (L:O).

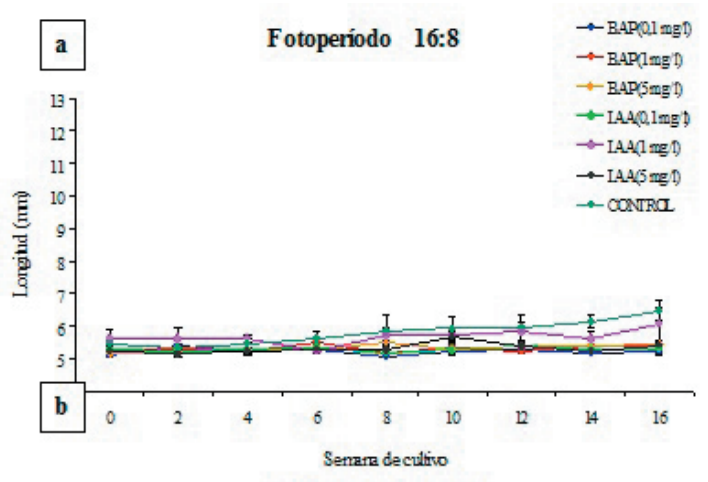

Fotoperíodo 12:12

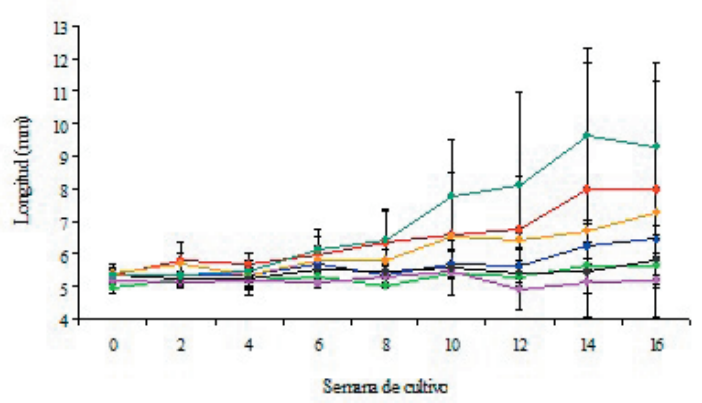

Fig. 16. Efecto de los reguladores de crecimiento de plantas superiores sobre la longitud de talos $(\mathrm{mm})$ en el tiempo (semana de cultivo) para porciones medias de talos de A. plicata. En distintas condiciones de fotoperíodo: a) fotoperíodo: 16:8 (L:O) y b) fotoperíodo 12:12 (L:O).

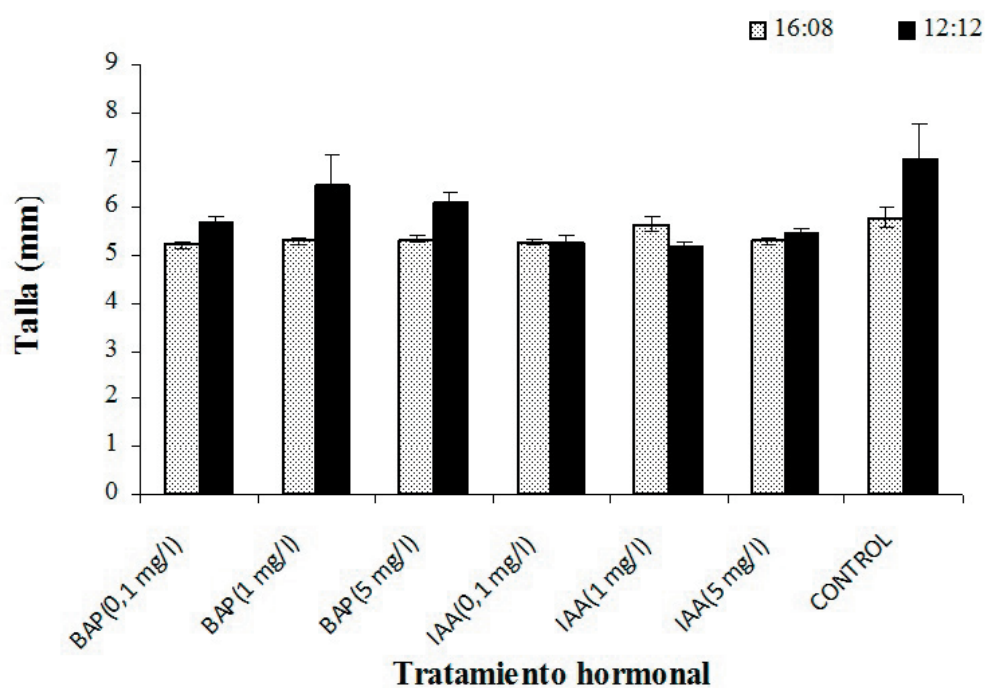

Fig. 15. Interacción entre tratamiento hormonal y fotoperíodo sobre la talla promedio de porciones medias de talos de A. plicata. Barras de error corresponden a los errores estándar. BAP: 6-bencilaminopurina; IAA: Ácido Indolacético. 


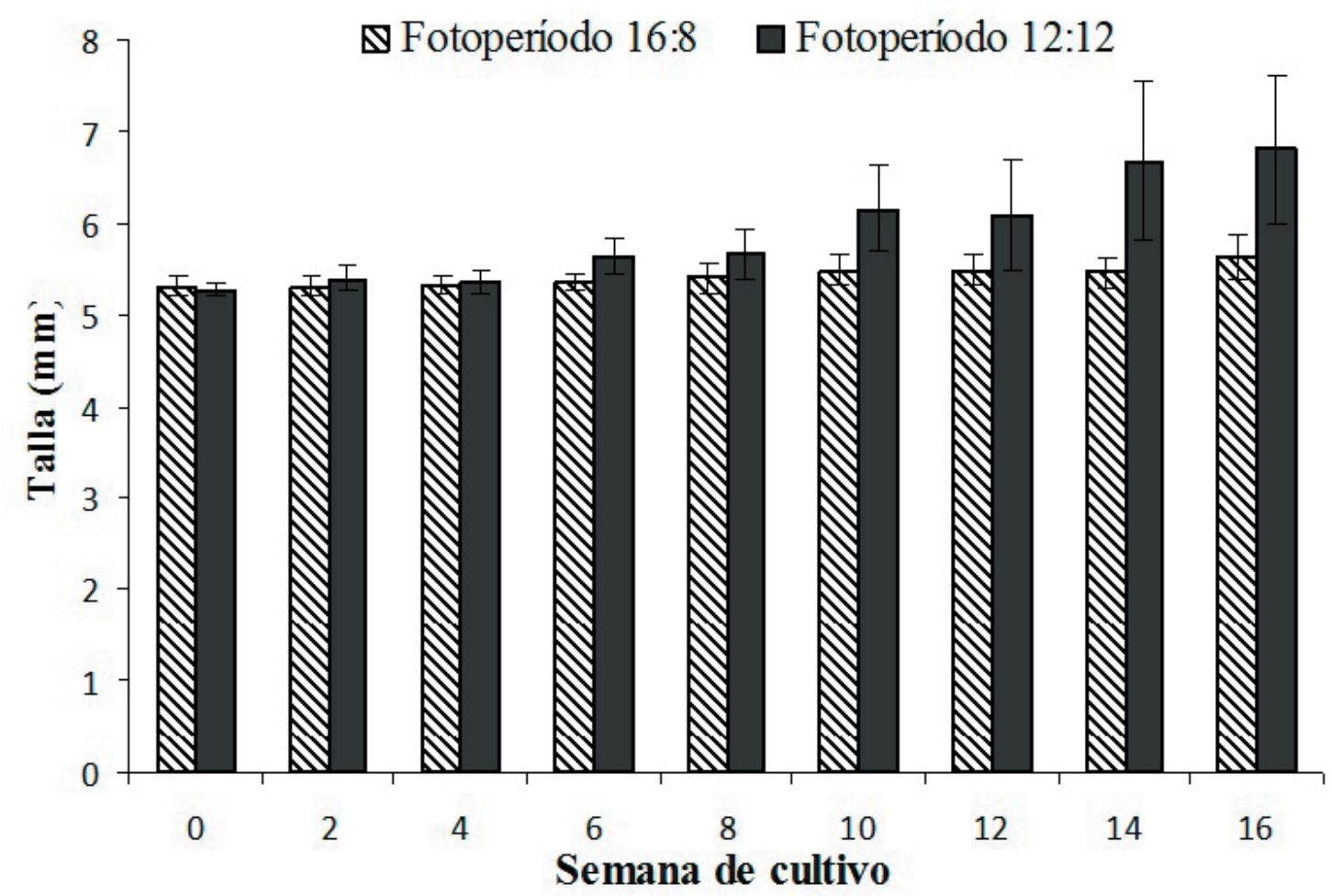

Fig. 17. Efectos en el crecimiento de segmentos de A. plicata por la interacción entre fotoperíodo y tiempo (semana de cultivo) entre los dos tratamientos

La fig. 13 muestra los análisis de los resultados de crecimiento (longitud) de porciones apicales utilizando los diferentes reguladores de crecimiento en las dos condiciones de cultivo utilizadas, donde se aprecian dos interacciones significativas (Tabla 1), la primera de ellas corresponde a la dependencia entre fotoperíodo $(\mathrm{F})$ y sustancias reguladoras de crecimiento $(\mathrm{H})$, donde en términos comparativos, el tratamiento con reguladores de crecimiento de plantas superiores BAP (1 mg/L) en fotoperíodo 12:12 (L:O) muestra longitudes significativamente superiores al resto de los tratamientos utilizados, incluyendo el tratamiento control. La segunda interacción observada se manifiesta entre los factores reguladores de crecimiento $(\mathrm{H})$ y el tiempo transcurrido desde el inicio del experimento (T). El tratamiento con fotoperíodo 16:8 (L:O) claramente no estimula el crecimiento en longitud de los talos, observándose que después de 16 semanas de cultivo, la longitud promedio de los talos se incrementó apenas levemente (Fig. 14 a). Sin embargo, es importante resaltar la clara diferenciación en tamaño a partir de la semana 12, para el caso del tratamiento experimental con BAP a concentración $1 \mathrm{mg} / \mathrm{L}$ en el tratamiento 2 (fotoperíodo 12:12 (luz: oscuridad)) (Fig. 14 b), destacándose una importante interacción entre estas dos variables.

En cuanto a los explantes de región media, hubo 3 interacciones significativas entre: fotoperíodo - tratamiento hormonal; fotoperíodo - tiempo y tratamiento hormonal - tiempo (tabla 2), observándose la existencia de una relación entre el fotoperíodo y el tipo de hormona utilizada (Fig. 15). En general, los tratamientos con BAP y fotoperíodo 12:12 muestran mejores niveles de crecimiento que aquellos con IAA. Sin embargo, estos no difieren de la longitud promedio en el tratamiento control con Provasoli

Se observó un mayor incremento sobre la longitud las porciones medias del talo atribuibles al control, observándose partir de la semana 10 incrementos significativos en comparación al resto de los tratamientos hormonales. Los explantes 
TABLA 2. Efectos sobre cambios en talla de las porciones medias de talos de A. plicata (ANDEVA). Se destacan tres interacciones significativas. F: Fotoperíodo; T: tiempo (semanas) y H: tratamiento hormonal.

\begin{tabular}{lcccccc}
\hline Efecto & gl efecto & CM efecto & gl error & CM error & F & p \\
\hline Fotoperíodo (F) & 1 & 21,17 & 252 & 0,46 & 46,103 & $<0,001$ \\
Hormona (H) & 6 & 8,68 & 252 & 0,46 & 18,896 & $<0,001$ \\
Tiempo $(\mathrm{T})$ & 8 & 4,70 & 252 & 0,46 & 10,240 & $<0,001$ \\
F x H & $\mathbf{6}$ & $\mathbf{5 , 4 2}$ & $\mathbf{2 5 2}$ & $\mathbf{0 , 4 6}$ & $\mathbf{1 1 , 8 1 0}$ & $<\mathbf{0 , 0 0 1} *$ \\
F x T & $\mathbf{8}$ & $\mathbf{2 , 3 2}$ & $\mathbf{2 5 2}$ & $\mathbf{0 , 4 6}$ & $\mathbf{5 , 0 5 5}$ & $<\mathbf{0 , 0 0 1} *$ \\
H x T & $\mathbf{4 8}$ & $\mathbf{0 , 7 6}$ & $\mathbf{2 5 2}$ & $\mathbf{0 , 4 6}$ & $\mathbf{1 , 6 4 9}$ & $\mathbf{0 , 0 0 8} *$ \\
F x H x T & 48 & 0,44 & 252 & 0,46 & 0,951 & 0,569 \\
\hline
\end{tabular}

mantenidos con BAP a concentraciones de 1 y 5 $\mathrm{mg} / \mathrm{L}$, muestran tendencias de crecimiento similares al control, (Fig. 16). Se aprecia, que la talla promedio de regiones medias de los talos de A. plicata aumentan a partir de la semana 10 para la condición 12:12 de fotoperíodo (Fig. 17).

\section{DISCUSIÓN Y CONCLUSIONES}

Auxinas y citoquininas promueven el crecimiento de segmentos apicales y porciones medias de talo de Ahnfeltia plicata, estimulando la división celular. Yokoya \& Handro (1996, 1997), observaron crecimiento en regiones apicales y porciones medias de talos en Grateloupia dichotoma J. Agardh (1842) con estimulación de la división celular y /o alargamiento de las células al utilizar reguladores de crecimiento de plantas superiores. Collantes et al. (2004) a pesar de haber trabajado con condiciones nutricionales diferentes (auxinas y kinetinas) en el cultivo de G. chilensis C.J. Bird, McLachlan \& E.C. Oliveira, obtuvieron respuestas similares en todos los tratamientos, explicando que los tejidos cultivados tuvieron las reservas necesarias para el desarrollo de las estructuras observadas.

El crecimiento de los explantes con desarrollo de callos en A. plicata se observó tanto en cultivos con reguladores de crecimiento de plantas superiores como en los controles, lo que indica que el desarrollo de estas estructuras fue inducido por procesos de cicatrización, más que por efecto de adición de estas sustancias (Yokoya \& Handro, 1997). PolneFuller \& Gibor (1987) realizaron experimentos de cultivo con diferentes medios de cultivo (agua de mar, Provasoli, ASP-C-1, ASP12NTA, TC-1, ASP6F2 y medio Murashige \& Skoog modificado preparado en agua de mar), utilizando Enteromorpha intestinalis (Linnaeus) Nees, Ulva angusta (Setchell \& N. L. Gardner), Porphyra perforata (J. Agardh), Smithora naiadum (C. L. Anderson) Hollenberg, Macrocystis pyrifera (Linnaeus) C. Agardh, Egregia menziesii(Turner) Areschoug, Sargassum muticum (Yendo) Fensholt, Pelvetia fastigata (J. Agardh) De Toni, Cystoseira osmundacea (Turner) C. Agardh, Gracilaria papenfussii I. A. Abbott, Gelidium nudifrons N. L. Gardner, Gelidium robustum (N. L. Gardner) y Gigartina exasperata Harvey \& J. W. Bailey, mostrando que la formación de callos de muchas especies de algas se produce con medio de cultivo no enriquecido, lo que coincide con lo observado en experimentos de micropropagación realizados anteriormente, en los cuales sólo se utilizó Provasoli sin TRIS buffer y agar - agar (Villanueva et al., 2010).

Collantes et al. (2004) desarrollaron un experimento utilizando el alga roja Gracilaria chilensis C.J. Bird, McLachlan \& E.C.Oliveira, utilizando una variedad de condiciones experimentales y observaron que hubo desarrollo de callos en polos basales y apicales de regiones medias de esta especie, además de formación de brotes, y concluyeron que los callos apicales (del tipo medular y cortical) estaban relacionados con el desarrollo de yemas apicales, en cambio de los callos basales (sólo de tipo cortical) estaban relacionados con procesos de inducción de la cicatrización en estos talos.

En este estudio, se observó que cultivos enriquecidos con auxina (IAA) estimularon 
escasamente el crecimiento en las regiones polares de explantes de A. plicata tanto en porciones apicales como medias del talo. La presencia de esta hormona no indujo la formación de ramificaciones laterales de los mismos, sin embargo al utilizar citoquinina (BAP) se observó crecimiento tanto de las regiones polares así como diferenciación y formación de ramificaciones laterales del talo. La presencia de ramificaciones laterales en explantes mantenidos con IAA, puede ser producto de que al momento de comenzar el estudio, estas estructuras hayan estado en proceso de crecimiento y se estimuló el crecimiento con el uso de medio de cultivo enriquecido con reguladores de crecimiento de plantas superiores. Según Yokoya \& Handro (1997), el efecto inhibitorio de las auxinas sobre la morfogénesis, en contraste con efectos estimulantes de las citoquininas sobre la formación de estas ramificaciones laterales, es muy similar a lo observado en plantas vasculares. Además, mencionan que el efecto de altas concentraciones de citoquinina podría estar relacionado con la división celular ya que incrementa la síntesis de proteínas y actividad metabólica, afectando los procesos de diferenciación celular, lo que podría explicar el crecimiento de ramas laterales en los explantes.

Los resultados demostraron que el proceso de regeneración de los explantes fue estimulado principalmente con el uso de citoquinina (BAP) a una concentración de $1 \mathrm{mg} / \mathrm{L}$ y en cultivos mantenidos en fotoperíodo 12:12 (luz:oscuridad) y a $10^{\circ} \mathrm{C}$ (tratamiento 2), ya que presentaron un mayor crecimiento, aunque se observó necrosis temprana y mayor decoloración de los tejidos cultivados bajo estas condiciones, similar a lo observado por Yokoya et al. (1999) en explantes de Gracilaria vermiculophylla (Ohmi) Papenfuss en Japón. No se detectaron diferencias significativas atribuibles a ninguno de los tratamientos en este estudio. Es importante mencionar que algunas sustancias reguladoras de crecimiento pueden ser producidas por bacterias epífitas u hongos (Lobban \& Harrison 1994). Si bien se utilizó un pre-tratamiento antibiótico-antimicótico previo al experimento, no se puede descartar alguna acción de estas sustancias en los resultados obtenidos en este estudio.

En cuanto al desarrollo de la cubierta blanquecina (cubierta hialina), es importante mencionar que ha aparecido en cultivos in vitro de la especie. Debido a la poca información y al escaso conocimiento sobre la biología de la especie, se continúan realizando estudios para determinar la eventual importancia de estas estructuras.

\section{AGRADECIMIENTOS}

Se agradece a Sebastián Rosenfeld y Johanna Marambio por la colecta de material biológico en Isla Riesco, Región de Magallanes. Los autores agradecen el financiamiento otorgado por FONDEF al proyecto D08I163. A. Mansilla, agradece a PFB23 (Basal-CONICYT), P05-002 (ICM-MIDEPLAN).

\section{LITERATURA CITADA}

Butler, D. M. \& Evans, L. V. (1990). Cell and tissue culture of macroalgae. In: I. Akatsuka (Ed.) Introduction to Applied Phycology. (pp. 629 - 645). Netherlands: SPB Academic Publishing, The Hague.

Chen, L. C., \& Taylor, A. R. (1978). Medullary tissue culture of the red alga Chondrus crispus. Canadian Journal of Botany. 56, 883 - 886. Collantes, G. C., Melo, C., \& Candia, A. (2004). Micropropagation by explants of Gracilaria chilensis Bird, Mc Lachlan and Oliveira. Journal of Applied Phycology. 16, 203- 213.

Evans, L. V., \& Trewavas, A. J. (1991) Is algal development controlled by plant growth substances? Journal of Phycology. 27, 322 -326.

García- Reina, G., Gómez- Pinchetti, J. L., Robeldo, D. R., \& Sosa, P. (1991). Actual potencial and speculative applications of seaweed cellular biotechnology: some specific comments on Gelidium. Hydrobiologia, 221, 181- 194.

Lobban, C. S., \& Harrison, P. J. (1994) Seaweed Ecology and Physiology. New York. Cambridge University Press.

Maggs, C. A. \& Pueschel, C. M. (1989). Morphology and development of Ahnfeltia plicata (Rhodophyta): proposal of Ahnfeltiales ord. Nov. Journal of Phycology, 25, 333-351.

McLachlan, J. (1973). Culture media - marine. In J. R.Stein (Ed.) Handbook of Phycological Methods (pp. 25 - 51).Cambridge, NY: Cambridge University Press.

Polne- Fuller, M., \& Gibor, A. (1987). Calluses and callus-like growth in seaweeds: Induction and culture. Hydrobiologia, 151/152, 131-138.

Polne- Fuller, M. (1988). The past, present and 
future, of tissue culture and biotechnology of seawweds. In T. Stadler, J. Mollion, M. C.Verdus, Y. Karamanos \& M. Christan (Eds.), Algal Biotechnology (pp. 17 - 31). London: Elsevier Applied Science.

Reddy, C. R., Jha, B. \& Fujita Y. (2008). Seaweed micropropagation techniques and their potentials: an overview. Journal of Applied Phycology, 20, 609 - 617.

Villanueva, F. A, Ávila, M. P, Mansilla, A. O. \& Cáceres J. H. (2010). Desarrollo de técnicas de micropropagación in vitro de Ahnfeltia plicata (Hudson) Fries, 1836 (Ahnfeltiales, Rhodophyta) de la Región de Magallanes. En Resúmenes XXX Congreso de Ciencias del Mar (p. 179). Universidad Católica de la Santísima Concepción, Concepción.

Yokoya, N. S., \& Handro, W. (1996). Effects of auxins and cytokinins on tissue culture of Grateloupia dichotoma (Gigartinales, Rhodophyta). Hydrobiologia, 326/327, 393- 400.

Yokoya, N. S. \& Handro, W. (1997). Thallus regeneration and growth induced by plant growth regulators and light intensity Grateloupia dichotoma (Rhodophyta). In T. Kitamura, (Ed.) Proceedings of I.T.I.T. International Symposium on New Technologies from Marine-Sphere (pp. 83-86). Takamatsu: Shikoku National Industrial Research Institute.

Yokoya, N. S., Kakita, H., Obika, H., \& Kitamura, T. (1999). Effects of environmental factors and plant growth regulators on growth of the red alga Gracilaria vermiculophylla from Shikoku Island, Japan. Hydrobiologia, 398/399, 339- 347. 
